\title{
PENERAPAN ELECTRONIC CUSTOMER RELATIONSHIP MANAGEMENT (E-CRM) DALAM UPAYA MENINGKATKAN PENDAPATAN PENJUALAN PADA PT. CIPTA ANEKA BUAH
}

\author{
Wendy William ${ }^{1}$, Bullion Dragon Andah ${ }^{2)}$ \\ ${ }^{1}$ Sistem Informasi, Fakultas Teknologi Informasi, Universitas Budi Luhur \\ ${ }^{1,2} \mathrm{JI}$. Raya Ciledug, Petukangan Utara, Kebayoran Lama, Jakarta Selatan 12260 \\ E-mail : wendywilliamjhosep@gmail.com ${ }^{11}$, bullion.dragon@budiluhur.ac.id $^{22}$
}

\begin{abstract}
Abstrak
PT. Cipta Aneka Buah merupakan perusahaan distributor buah dan sayuran import dan lokal. PT. Cipta Aneka Buah memiliki berbagai macam varian buah dan sayur impor maupun lokal yang berkualitas dan terjamin keamanannya. PT. Cipta Aneka Buah memiliki tempat penyimpanan (cold storage) yang luas, sehingga kesegaran buah dan sayur terjaga hingga ke tangan pelanggan. Akan tetapi banyak permasalahan diantaranya,banyak keluhan pelanggan yang tidak ditanggapi, pelanggan tidak mengetahui detail produk, dan kondisi produk saat ke tangan pelanggan sudah rusak.Oleh karena itu, diperlukanya E-CRM untuk mengatasi masalah tersebut. Peneliti bermaksud untuk membuat website dengan metode melakukan pengumpulan data yang sudah berjalan pada perusahaan seperti menganalisa dokumen, melakukan wawancara dan melakukan pendekatan dengan penarapan E-CRM sehingga website yang dibuat dapat menampilkan detail produk-produk, di website tersebut pelanggan dapat menuliskan keluhanya dan pelanggan dapat mengecek produk sudah sampai mana saat pengiriman. Dengan diterapkanya E-CRM dalam penelitian ini, peneliti berharap agar ECRM dapat mengatasi masalah tersebut dan mempertahankan omset penjualan yang tidak tercapai sehingga kepuasan pelanggan dan loyalitas pelanggan dapat terjaga.
\end{abstract}

Kata kunci: E-Crm, Meningkatkan pendapatan, perancangan.

\section{PENDAHULUAN}

Di era globalisasi yang berbasis IT seperti sekarang ini, dibutuhkan suatu sistem yang terdiri dari suatu kumpulan atau himpunan dari unsur, komponen, atau variabel yang terorganisasi, saling berinteraksi, saling bergantung satu sama lain dan terpadu [1] sebagai sarana dalam usahanya untuk meningkatkan Customer Relationship Management (CRM). Secara khusus mereka berusaha memberikan layanan yang sifatnya personal sehingga dapat memberikan kepuasan yang tinggi pada pelanggannya [2]. Dengan demikian diharapkan akan terjalin value chain yang kuat di antara mereka melalui customer relationship (hubungan dengan pelanggan). Untuk dapat meningkatkan CRM, perusahaan tidak segan melakukan investasi yang cukup mahal dan teknologi canggih yang mampu memberikan layanan yang maksimal bagi pelanggan atau yang biasa disebut E-CRM [3]. E-CRM merupakan strategi bisnis yang digunakan untuk mengefisiensikan suatu proses bisnis dalam sebuah perusahaan yang berkaitan dengan pelanggan [4].

PT. Cipta Aneka Buah merupakan perusahaan distributor buah dan sayuran import dan lokal. PT. Cipta Aneka Buah memiliki berbagai macam varian buah dan sayur impor maupun lokal yang berkualitas dan terjamin keamanannya. PT. Cipta Aneka Buah memiliki tempat penyimpanan (cold storage) yang luas, sehingga kesegaran buah dan sayur terjaga hingga ke tangan pelanggan. Akan tetapi banyak permasalahan diantaranya,banyak keluhan pelanggan yang tidak ditanggapi, pelanggan tidak mengetahui detail produk, dan kondisi produk saat ke tangan pelanggan sudah rusak.

Oleh karena itu, diperlukanya E-CRM untuk mengatasi masalah tersebut seperti membuat website yang menampilkan detail produk-produk, di website tersebut pelanggan dapat menuliskan keluhanya dan pelanggan dapat mengecek produk sudah sampai mana saat pengiriman.

Dengan diterapkanya E-CRM dalam penelitian ini, peneliti berharap agar E-CRM dapat mengatasi masalah tersebut dan mempertahankan omset penjualan yang tidak tercapai sehingga kepuasan pelanggan dan loyalitas pelanggan dapat terjaga.

\section{PENELITIAN SEBELUMNYA}

Banyak penelitian sebelumnya yang membahas tentang perancangan aplikasi berbasis CRM. Beberapa penelitian tersebut antara lain berjudul "Pengaruh faktor-faktor (CRM) terhadap kepuasan pelanggan” [6] Pada penelitian ini terdapat hasil analisis SEM dengan model termodifikasi, maka diketahui bahwa dua variabel terdapat satu variabel yaitu rewards yang secara positif berpengaruh signifikan terhadap kepuasan pelangggan. Untuk 
perbandingan penelitian ini dengan penelitian yang saat ini adalah Penelitian ini sama-sama menuju untuk kepuasan pelanggan akan tetapi Penelitian penulis kepuasan pelanggan ditandai dengan rating pada produk sedangkan referensi jurnal ditandai dengan reward

Penelitian lainnya berjudul "Perancangan Aplikasi Berbasis (CRM) untuk IKM Tas Yanri di Bogor" [7] Pada penelitian ini akan mencari tahu jawaban dari pertanyaan penelitian bagaimana bentuk rancangan sistem informasi berbasis Custumer Relationship Management (CRM) di IKM Tas Yanri. Mulai dari perancangan proses, data, sampai dengan perancangan antar mukanya, untuk membantu IKM Tas Yanri dalam hubungannya dengan para pelanggannya. Metode yang digunakan dalam penelitian ini adalah kualitatif, dengan jenis penelitiannya adalah deskriptif dan tindakan. Penelitian deskriptif untuk mendeskripsikan proses bisnis yang berjalan di IKM Tas Yanri, yang kemudian dianalisa dengan menggunakan konsep CRM, sehingga terlihat proses mana yang bisa dihilangkan, ditambah atau dimodifikasi. Penelitian tindakan untuk melakukan perbaikan proses bisnis dan selanjutnya melakukan perancangan sistem informasi berbasis CRM, yang terdiri dari perancangan proses menggunakan DFD, perancangan basis data menggunakan ERD dan perancangan antar muka. Metode pengumpulan data yang digunakan adalah wawancara mendalam kepada pemilik IKM Tas Yanri dan observasi langsung proses-proses yang terjadi di IKM Tas Yanri serta studi literatur. Hasil dari penelitian ini adalah Perancangan Proses, yang mempunyai 8 proses utama di dalamnya, yaitu (1) Proses Pendaftaran Pelanggan, (2) Proses Login Pelanggan Lama, (3) Program Pemasaran, (4) Program Penjualan, (5) Pengisian Produk, (6) Laporan, (7) Pelayanan Pelanggan, (8) Program Diskon. Pada hasil Perancangan Data sistem informasi CRM terdapat 8 buah entitas di dalamnya, yaitu entitas tanya jawab, keluhan, barang belum sampai, garansi, pelanggan, transaksi, produk, dan produk pesanan. Sedangkan hasil perancangan antar muka pada dasarnya terdiri dari 2 tampilan, yaitu tampilan halaman login dan tampilan halaman setelah login.

\section{METODE PENELITIAN}

Dalam penyusunan penelitian ini untuk memperoleh data dan informasi yang diperlukan identifikasi masalah, pengumpulan data dan teknik analisis data. Berikut penjelasanya :

\subsection{Identifikasi}

Untuk identifikasi masalah terdapat beberapa proses yang dilakukan seperti berikut: a. Analisa proses dengan metode pengumpulan data secara observasi, wawancara dengan pihak terkait, mengumpulkan dokumen serta menganalisanya dengan studi kepustakaan sesuai pembahasan.

b. Menganalisa proses bisnis berjalan dan mengidentifikasi masalah pada PT Cipta Aneka Buah, dan menggambarkannya ke dalam activity diagram.

c. Dari masalah yang ada kemudian digambarkan dengan fishbone diagram. Dengan fishbone diagram akan terlihat sebab akibat terjadinya masalah.

d. Dari hasil identifikasi kebutuhan dibuatkan model datanya dengan use case diagram dan activity diagram.

e. Menggambarkan model data dengan Entity Relationship Diagram (ERD) lalu transformasi menjadi Logical Record Structure (LRS).

f. Membuat rancangan prototype yang meliputi rancangan layar sistem yang akan digunakan, rancangan masukan dan rancangan keluaran.

\subsection{Metode Pengumpulan Data}

Untuk memperoleh kebutuhan data yang berhubungan dengan topik yang penulis ambil, maka penulis menggunakan beberapa metode pengumpulan data dalam memperoleh keterangan dari sistem berjalan yang ada pada saat ini, yaitu:

a. Observasi

Penulis melakukan pengamatan langsung ke bagian-bagian yang berhubungan dalam proses produksi, dan proses purchasing agar data yang diperoleh lebih lengkap.

\section{b. Wawancara}

Wawancara merupakan proses mengumpulkan data dengan cara bertatap muka langsung dengan mengajukan pertanyaan pada pihak yang terkait dengan arus proses pengadaanbahan baku sampai proses produksi. Pada kegiatan ini diajukan pertanyaan lisan dalam usaha untuk melengkapi data yang akan diperoleh.

c. Analisa Dokumen

Menganalisa dokumen berjalan agar mendapatkan informasi yang sesuai dengan kebutuhan sistem yang akan dibuat.

\subsection{Teknis Analisis Data}

Menganalisa data yang sedang berjalan guna menentukan solusi terhadap masalah yang terjadi. Dan untuk mempermudah proses penelitian dalam menganalisa masalah, adapun tahapan-tahapan sebagai berikut ini:

\section{a. Analisa Proses Bisnis}

Analisa proses bisnis pertama kali dilakukan dengan menguraikan proses bisnis yang didapat. Kemudian dibuatkan activity diagram berjalan 
dengan menggunakan software Rational Rose Enterprise. Di dalam activity diagram tersebut akan menggambarkan proses bisnis berjalan.

b. Identifikasi Masalah

Identifikasi masalah dibuat dengan menggambarkan fishbone diagram, dimana di dalam diagram tersebut diuraikan kembali penyebabpenyebab masalah. Fishbone Diagram dibuat dengan menggunakan Microsoft Office Visio 2013.

c. Perancangan Sistem Usulan

Untuk merancang sistem usulan, pemodelan sistem digambarkan dengan use case diagram dan activity diagram dibuat dengan menggunakan Rational Rose Enterprise Edition, sedangkan pemodelan data digambarkan dengan Entity Relationship Diagram (ERD) yang dibuat dengan menggunakan Rational Rose Enterprise.

\section{HASIL DAN PEMBAHASAN}

\subsection{Analisa Sistem Berjalan}

Analisa sistem berjalan merupakan sebuah penjelasan tentang proses-proses bisnis, permasalahan dan analisa sistem yang sedang digunakan saat ini. Berikut penjelasan di bawah ini : a. Analisa Proses Bisnis

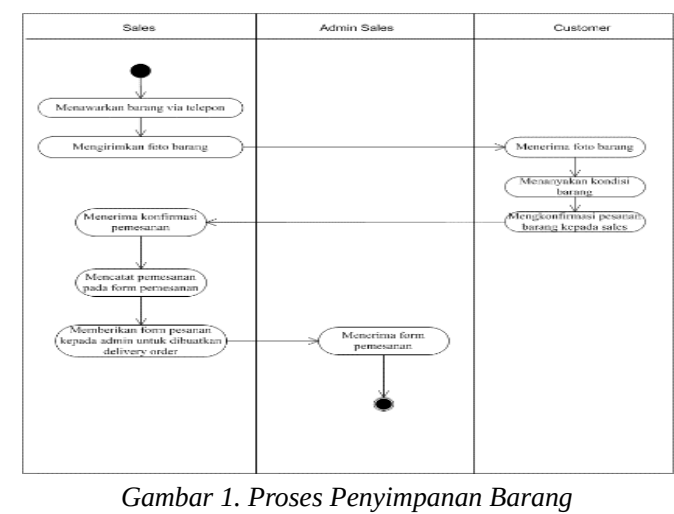

Pada gambar 1 terdapat analisa proses penyimpanan barang di PT. Cipta Aneka Buah.

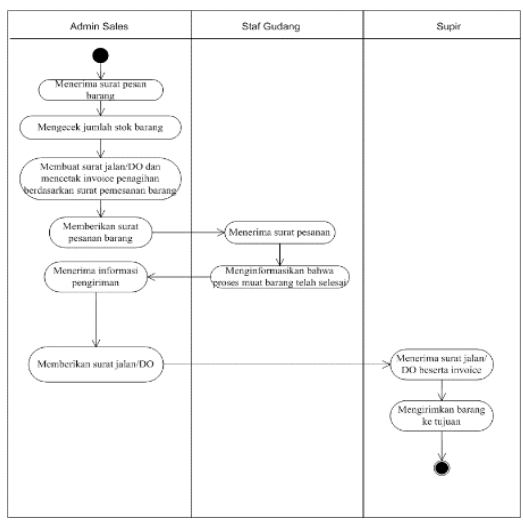

Gambar 2. Proses Pembuatan Delivery Order
Pada gambar 2 terdapat analisa proses pembuatan delivery order di PT. Cipta Aneka Buah.

b. Analisa Permasalahan

Merupakan permasalahan-permasalahan yang ada dalam penelitian ini. Dalam penelitian ini penulis menggunakan diagram fishbone sebagai analisis permasalahan [5]. Di bawah ini terdapat diagram fishbone pada gambar 3. :

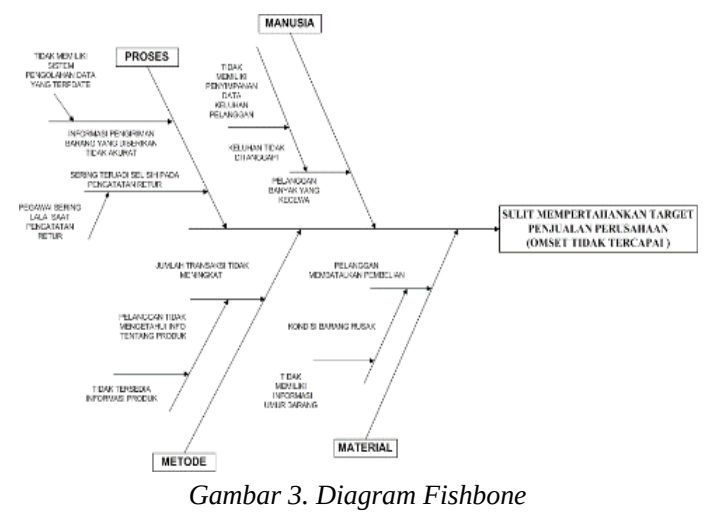

\subsection{Rancangan Sistem}

Rancangan sistem ini merupakan beberapa solusi untuk mengatasi analisis permasalahan di atas. Dalam rancangan system ini terdapat model sistem, model data dan rancangan sistem. Berikut penjelasanya

a. Model Sistem

Model sistem merupakan pemodelan dari sistem yang dirancang. Hasil rancanganya berdasarkan identifikasi kebutuhan yang didapat dari tahap sebelumnya. Pada model sistem terdapat package diagram dan use case diagram

\section{1) Package Diagram}

Pada package diagram kali ini ada beberapa package, yaitu package account, package master, package transaksi, package trace transaksi, package keluhan, package rating produk dan package laporan. Di bawah ini merupakan package diagram pada gambar 4:
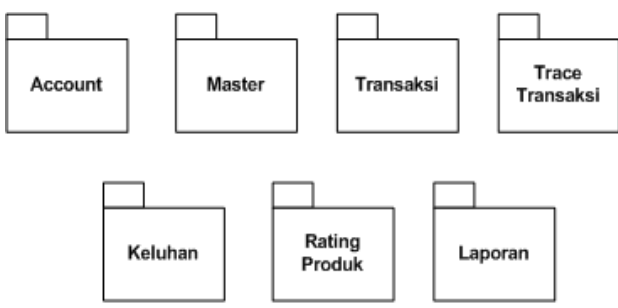

Gambar 4. Package Diagram

2) Use Case Diagram Usulan Account

Pada use case diagram account terdapat 3 actor yaitu : staff (admin), dan pelanggan. Yang mana untuk dapat masuk ke dalam system maka diperlukan hak akses berupa akun agar dapat masuk 
kedalam system. Aktifitasnya berupa login, ubah password dan logout. Berikut detail gambar diagram account pada gambar 5 :

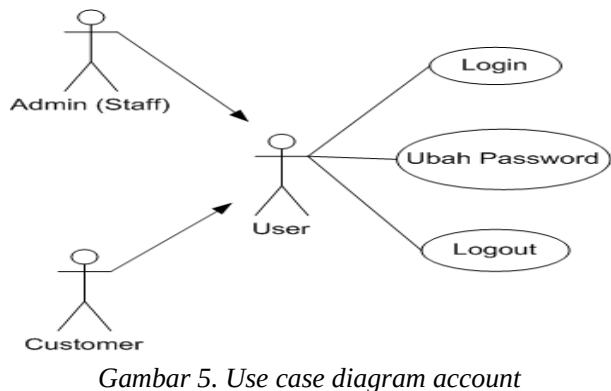

3) Use Case Diagram Master

Pada use case diagram master, actor mengelola data customer, mengelola data barang, mengelola data transaksi, mengelola data surat jalan dan invoice pesanan, mengelola data retur dan mengelola data keluhan. Yang dimaksud mengelola disini adalah input, update dan delete. Berikut detail gambar diagram master pada gambar 6 :

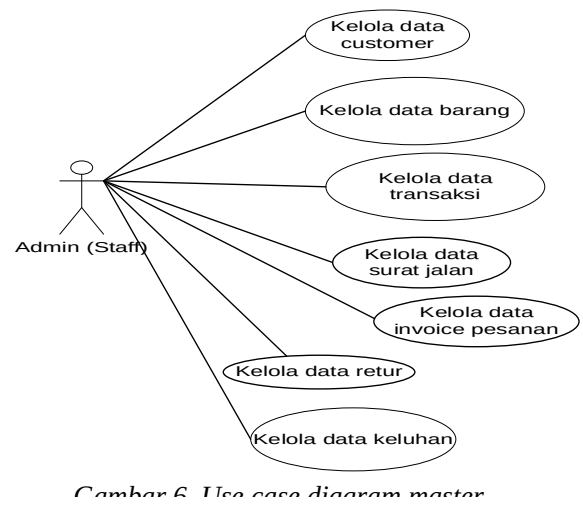

4) Use Case Diagram Transaksi

Pada diagram use case transaksi customer melakukan transaksi pemesanan barang, dan customer menerima resi pengiriman. Berikut detail gambar diagram transaksi pada 7 :

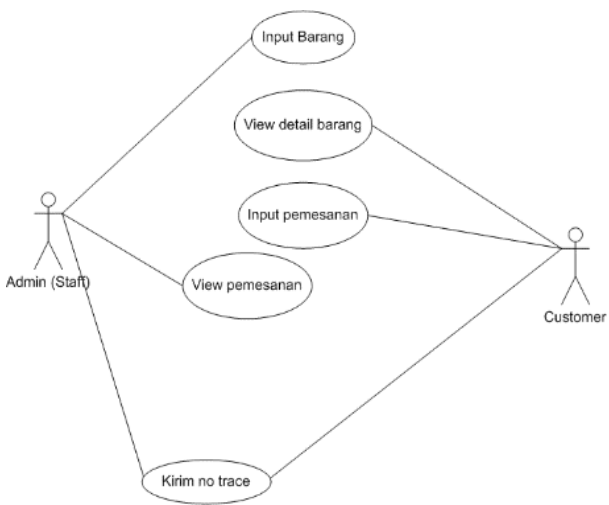

Gambar 7. Use case diagram transaksi
5) Use Case Diagram Mencetak Laporan

Pada use case diagram laporan adalah berupa cetakan laporan-laporan. Berikut detail gambar pada gambar 8 :

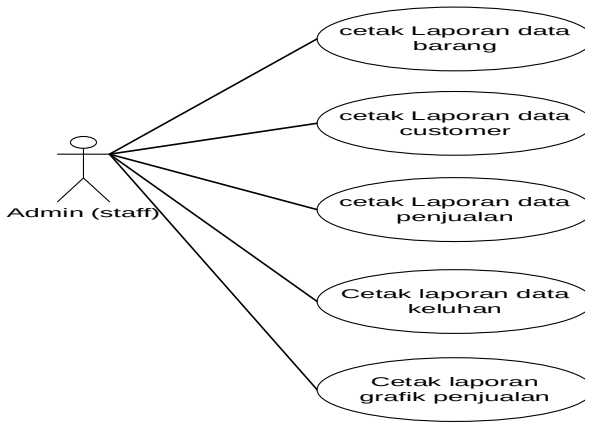

b. Model Data

Model data merupakan sebuah pemodelan yang diperoleh dari database. Di dalam pemodelan data berupa ERD, transformasi ERD ke LRS dan LRS. Berikut penjelasan dibawah ini :

1) ERD

Entity Relationship Diagram (ERD) adalah sebagai bentuk bagan yang menggunakan relasi dan entitas suatu informasi. Entitas relasi diagram dibuat dengan menggunakan presepsi yang terdiri dari sekumpulan objek yang ada serta dibedakan dari objek lain. Di bawah ini terdapat ERD pada gambar 9:

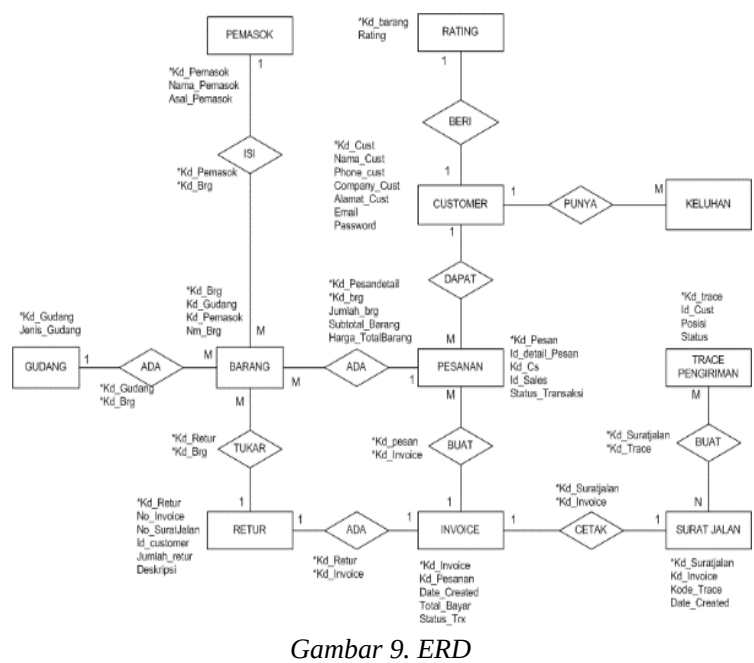

2) Transformasi ERD ke LRS

Transformasi Entity Relationship Diagram (ERD) ke Logical Record Structure (LRS) merupakan suatu kegiatan untuk membentuk datadata dari diagram hubungan entitas ke suatu LRS. Transformasi ini dibuat berdasarkan hubungan entitas (ERD) dengan memperhatikan tingkat hubungan (Cardinality) dari hubungan entitas tersebut. 
Untuk proses transfomasi ERD ke LRS E-CRM pada PT Cipta Aneka Buah maka dapat digambarkan sebagai berikut pada gambar 10:

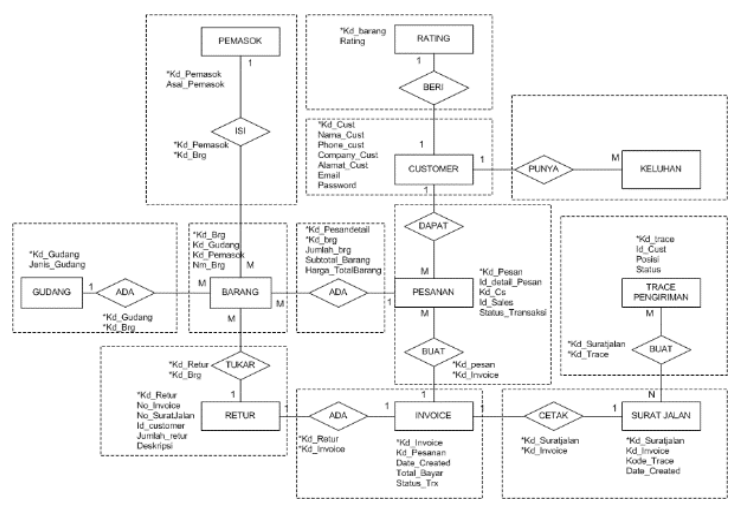

Gambar 10. Transformasi ERD ke LRS

\section{3) LRS}

LRS (logical record structure) adalah representasi dari struktur record-record pada tabeltabel yang terbentuk dari hasil antar himpunan entitas.

Untuk proses LRS E-CRM pada PT Cipta Aneka Buah maka dapat digambarkan sebagai berikut pada gambar 11:

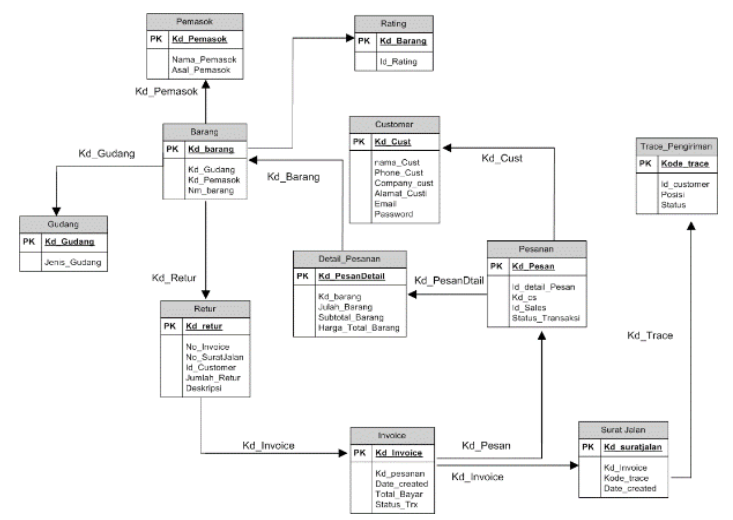

Gambar 11. LRS (logical record structure)

c. Rancangan Layar

Rancangan layar merupakan sebuah rancangan desain tampilan di dalam membuat sebuah system. Berikut detail rancangan-rancangan layarnya

\section{1) Rancangan layar login}

Rancangan layar login merupakan tampilan awal dalam mengelola website. Agar dapat masuk ke dalam system maka actor harus memiliki username dan password. System akan menampilkan tampilan menu utama jika inputan username dan password sesuai. Berikut rancanganya terdapat pada gambar 12:

\section{Selamat Datang Di Dashboard.}

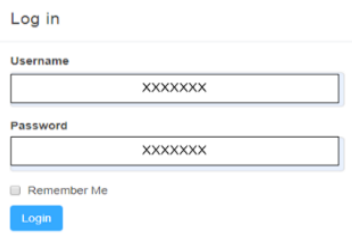

Gambar 12. Rancangan layar login

2) Rancangan layar dashboard admin

Merupakan halaman untuk berbagai macam pengelolaan data. Berikut rancangan layar dashboard admin pada gambar 13

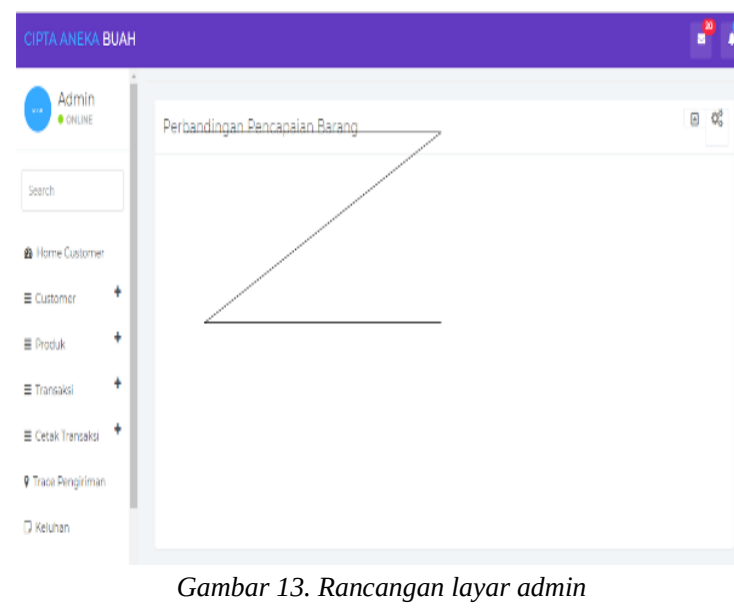

3) Rancangan layar customer

Merupakan data-data customer yang sudah melakukan pesanan. Berikut gambar dari rancangan layar customer pada gambar 14 :

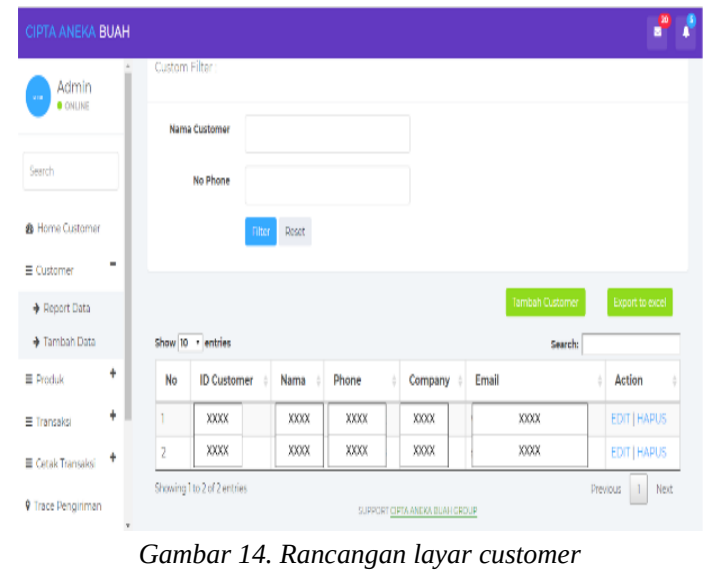

4) Rancangan layar slide show produk

Merupakan detail produk unggulan yang muncul di halaman awal customer. Berikut gambar dari rancangan layar slide show produk pada gambar 15 : 


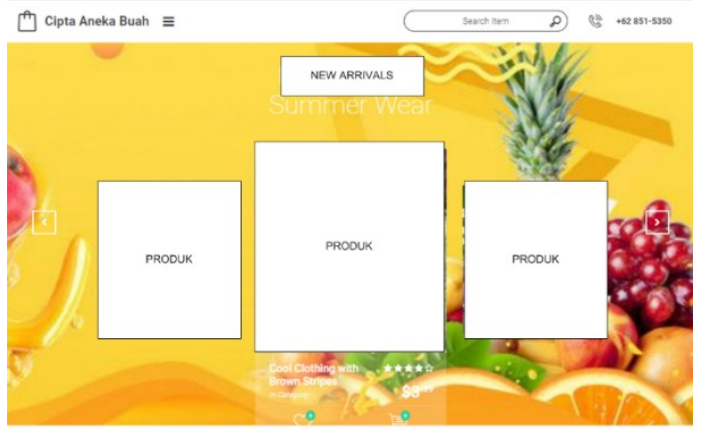

Gambar 15. Rancangan layar slide show

d. Korelasi Masalah dan Solusi

Merupakan penanganan masalah yang akan diselesaikan oleh solusi solusi. Berikut penjelasanya di bawah ini

1. Adanya form update untuk memberikan informasi keberadaan barang pada saat pengiriman berlangsung

2. Adanya form upload foto untuk memberikan informasi produk dari setiap negara asal

3. Adanya data retur yang terupdate

4. Membuat halaman / form keluhan pelanggan

\section{KESIMPULAN}

Berdasarkan analisa yang telah dilakukan dapat ditarik kesimpulan sebagai berikut :

a) Masalah selisih pada retur barang dapat diatasi dengan dibuatkannya sistem pencatatan data retur yang sesuai dan akan tersimpan di dalam database.

b) Masalah tidak adanya pencatatan keluhan pelanggan yang tidak terkomputerisasi maka dapat teratasi dengan dibuatkan sistem form keluhan pelanggan sehingga keluhan pelanggan dapat ditanggapi dan keluhan pelanggan dapat tersimpan dengan baik di dalam database.

c) Masalah pelanggan tidak mengetahui posisi barang yang dipesan dapat teratasi dengan dibuatkannya sistem yang dapat menampilkan lokasi posisi barang yang sedang dipesan saat ini, sehingga pelanggan dapat mengetahui dimana lokasi posisi barang yang sedang dipesan.

d) Masalah pelanggan tidak mengetahui detail produk dapat teratasi dengan dibuatkan sistem yang dapat menampilkan secara detail produk, sehingga pelanggan dapat mengetahui secara detail produk tersebut.

\section{DAFTAR PUSTAKA}

[1] Sutabri. Analisis Sistem Informasi. Yogyakarta. 2012
[2] Hasibuan. Manajemen Perubahan. Jakarta. 2012

[3] Farooqi, Dhusia. A Comparative Study Of Crm And E-Crm Technologies. Computer Science and Engineering. P.624-627. 2011

[4] Fjermestad. Electronic Customer Relationship Management. New York. 2015

[5] Saeger, The Ishikawa Diagram: Identify Problems and Take Action (First Edit). 2015

[6] Riswan E. Tarigan, Arnon M Sugiharto, Andree E. Widjaja. 2017. Pengaruh faktor-faktor Customer Relationship Management (CRM) terhadap kepuasan pelanggan : Studi Kasus Hypermart. Jakarta

[7] Yan Andriariza AS. Perancangan Aplikasi Berbasis (CRM) untuk IKM Tas Yanri di Bogor. 2013 